\title{
Civil Applications Committee
}

To help keep the public safe from the threat of active volcanoes, a team within the National Civil Applications Center (NCAC) at the U.S. Geological Survey (USGS) headquarters in Reston, Virginia, coordinates remote sensing technologies in support of worldwide volcano and disaster monitoring efforts by leveraging satellite sensors and systems provided through the U.S. Intelligence Community and Department of Defense assets. Volcano monitoring is one example of the many diverse missions that the Civil Applications Committee (CAC) oversees and facilitates.

\section{Mission}

The interagency CAC facilitates the appropriate civil uses of overhead remote sensing technologies and data collected by military and intelligence capabilities, including from commercial sources. The CAC is operated and staffed by the USGS on behalf of the U.S. Department of the Interior (DOI). The director of the USGS is the chair of the committee, and the vice-chair is a non-DOI senior official. The CAC ensures certain Federal civil agencies have access to these remotely sensed assets to meet their statutory missions in ways that do not threaten the civil rights, civil liberties, and personal privacy of U.S. citizens. To meets its mandate, the CAC hosts various working groups and communities of interest including those focused on thermal issues (wildland fires and volcanoes), environmental security, and historical satellite imagery. CAC-sponsored activities include a variety of initiatives, such as the following:

- Detecting, monitoring, assessing, and responding to natural disasters

- Monitoring environmental conditions

- Conducting Earth system scientific research

- Contributing to land use and natural resource management

- Supporting law enforcement, regulatory, and homeland security missions

- Disseminating remote sensing information and products to support national policies and objectives

- Mapping, charting, and geodesy

\section{At the Triple Junction}

The Civil Applications Committee operates at the triple junction of the intelligence, defense, and Federal civil communities on geospatial-intelligence and remote sensing issues.

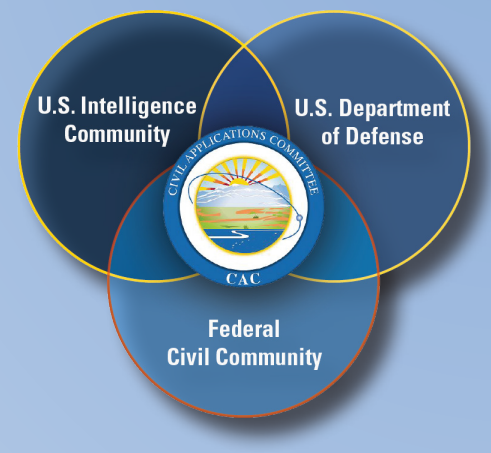

\section{Oversight}

CAC oversight responsibilities include disseminating information to Federal users on policies related to the proper civil use of the data and the protection of intelligence sources and methods. The CAC receives, reviews, and approves all civil requests, assigns priorities to such requests, and acts as the interface between the Federal civil agencies and the intelligence and defense communities. Through the CAC, pertinent knowledge on the use of remote sensing capabilities is distributed to civil community members. The CAC also represents the civil community in national security forums and serves as an advocate for policies and technologies of common benefit to the civil, defense, and intelligence communities.

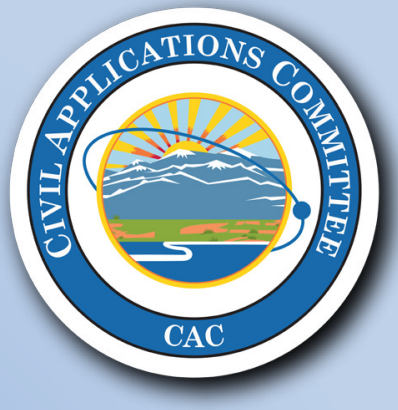

\section{Principal (Voting) Members}

U.S. Department of the Interior

U.S. Department of Agriculture

U.S. Department of Commerce

U.S. Department of Health and Human Services

U.S. Department of Transportation

U.S. Agency for International Development

U.S. Army Corps of Engineers

U.S. Coast Guard

U.S. Environmental Protection Agency

Federal Emergency Management Agency

National Science Foundation

National Aeronautics and Space Administration

Tennessee Valley Authority

\section{Associate (Nonvoting) Members}

U.S. Department of State

U.S. Department of Energy

U.S. Department of Homeland Security

National Reconnaissance Office

Defense Intelligence Agency

National Geospatial-Intelligence Agency

National Guard Bureau

\section{Ex Officio Members}

Office of the Director of National Intelligence

Office of Science and Technology Policy

National Geospatial Intelligence Committee

\section{Public Safety}

During the 2018 lower East Rift Zone eruption of Kîlauea Volcano, the CAC oversaw the daily use of U.S. Intelligence Community remote sensing capabilities to assist the USGS Hawaiian Volcano Observatory in map production and information sharing with local officials, decision makers, and the public on eruption progression and potential hazards.

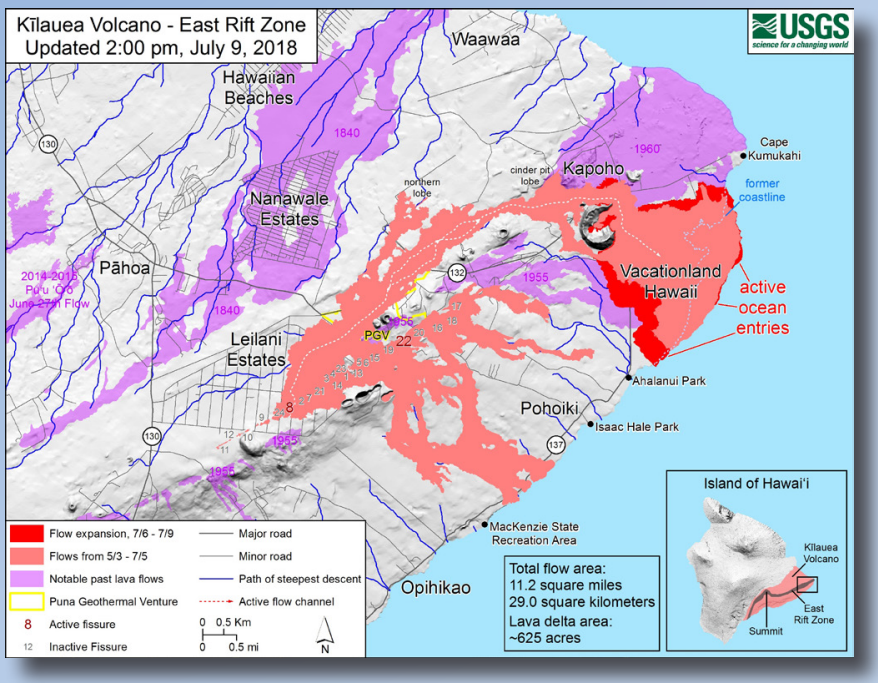




\section{History}

In 1960, the Central Intelligence Agency (CIA) launched CORONA, the Nation's first classified reconnaissance satellite. By the late 1960s, the USGS opened its own secure facility and was using Corona photography to revise and update its topographic maps and for geologic and resource assessments. To provide necessary oversight of Intelligence Community capabilities, President Ford directed the Secretary of the Interior in 1975 to establish the Civil Applications of Classified Overhead Photography of the United States, today known as the CAC (White House, 1975, p. 1). The Secretary of the Interior and the Director of National Intelligence cosigned the most recent charter in 2017.

To meet the growing need for environmental information, the CIA established the MEDEA program, a partnership between the U.S. Intelligence Community and 70 scientists that covered the major aspects of environmental science, in 1993 (Baker and Zall, 2020, p. 21). Among its many efforts, the MEDEA program developed the Global Fiducials Program (GFP). The GFP was a systematic effort to "image, store, and eventually declassify information" on specific environmentally sensitive sites, enabling study by current and future Earth scientists (Baker and Zall, 2020, p. 23). CAC assumed responsibility for the GFP in 1998 and started, with the USGS, the Global Fiducials Library (GFL).

\section{Global Fiducials Library}

The GFL brings together the data collection capabilities of the U.S. National Imagery Systems (USNIS) and the data needs of environmental scientists through the sponsorship of the CAC. Since the 1990s, the GFL has systematically imaged more than 500 environmentally sensitive "fiducial sites" around the world to understand Earth's dynamic environmental processes, variabilities, and changes on multiple scales. A fiducial site is defined as a geographic location to be used as an environmental benchmark for an environmentally significant site. These fiducial sites are for the long-term monitoring of processes, both natural and anthropogenic, associated with the causes or effects of environmental change.

The GFL has been making imagery time series of selected sites publicly available through the generation of unrestricted imagery derived products: http://gfl.usgs.gov.

\section{International Charter}

The CAC also supports the 20-year-old International Charter Space and Major Disasters, a worldwide collaboration among 129 countries to share disaster-related imagery data free of charge with civil protection authorities and the international humanitarian community (see: https://disasterscharter.org/). These historic CAC efforts consistently lead to new applications using defense and Intelligence Community remote sensing data and technology.

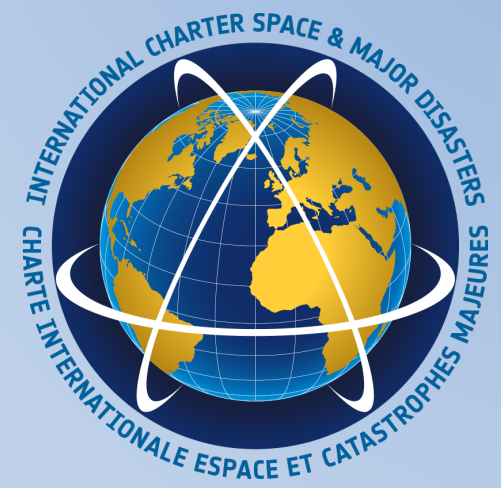

Image credit: International Charter Space and Major Disasters; used with permission.
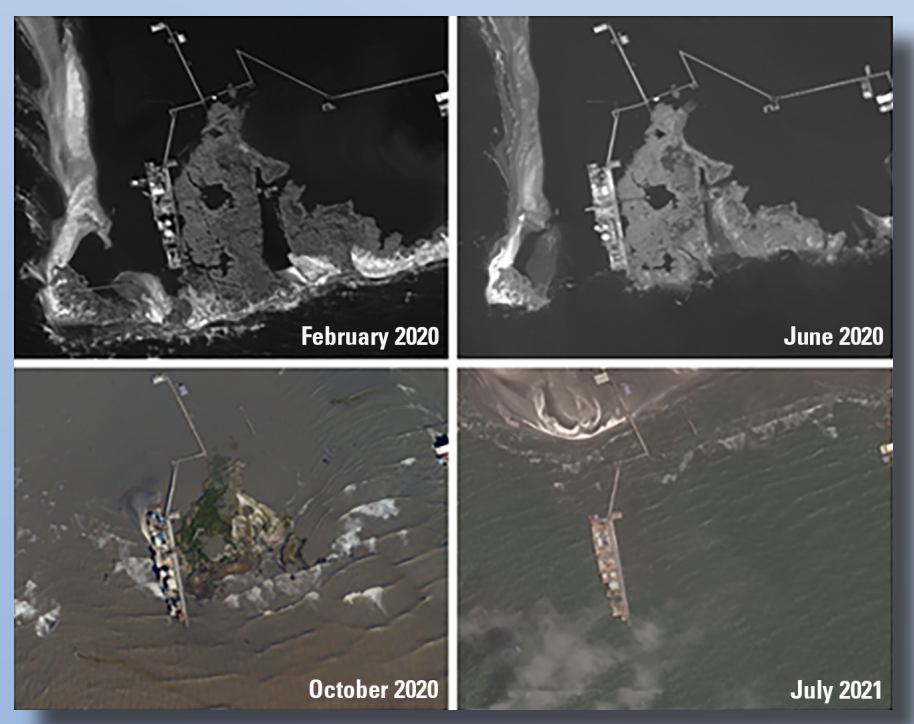

The USGS NCAC monitored dramatic changes at East Timbalier Island, a Gulf of Mexico barrier island on the west side of the Mississippi River Delta. The imagery was collected by USNIS and archived within the USGS GFL. New research expands this study both retrospectively and prospectively using declassified imagery collected in 1962 and 1972; Landsat imagery collected since 1972; aerial photography collected since 1953; and GFL imagery collected from 1991 to 2020. Images from Slonecker and others (2020).

\section{Forums}

CAC meetings are held monthly and consist of experts providing informational briefings and status updates on USNIS operations. CAC working groups and communities of interest meet as needed and are established to address specific CAC programs and issues for a wide array of disaster and science analysis missions. The CAC is funded by the USGS National Land Imaging Program and managed by the NCAC. NCAC facilities are hosted by the USGS in Reston, Virginia, and Lakewood, Colorado.

\section{References Cited}

Baker, D.J., and Zall, L., 2020, The MEDEA program — Opening a window into new Earth science data: Oceanography, v. 33, no. 1, p. 20-31, accessed July 2021 at https://doi.org/10.5670/ oceanog.2020.104.

Slonecker, E.T., Fisher, G.B., Dilles, S.J., Molnia, B.F., and Angeli, K.M., 2020, Six decades of change at East Timbalier Island, Louisiana: U.S. Geological Survey data release, https://doi.org/10.5066/ P9071HYS.

White House, 1975, Establishment of the Committee for Civil Applications of Classified Overhead Photography of the United States [memorandum]: The White House, received by the U.S. Department of Interior October 6, 1975, 2 p., accessed July 2021 at https://nsarchive2.gwu.edu/NSAEBB/NSAEBB229/18.pdf.

By Daniel W. Opstal and Ross T. Rogers

\section{For more information:}

CAC Secretariat (cac@usgs.gov),USGS

12201 Sunrise Valley Drive, MS 562

Reston, VA 20192

703-648-4493

Publishing support by the Reston and Rolla Publishing Service Centers 